\title{
Site Investigation of Groundwater Potential at Jasin Using Electrical Resistivity Imaging
}

\author{
Ahmad Hakimi Mat Nor ${ }^{1 \mathrm{a}}$,Miswan Surip ${ }^{2 \mathrm{a}}$, Khairul Zaman Abdul \\ Malek ${ }^{3 a}$, Mohd Erwan Sanik ${ }^{4 a}$,Salman Salim ${ }^{5 a}$, Mohammad Nasir Mohamad \\ Taher $^{6 \mathrm{~b}}$, Muhamad Wazir Shafix Osman ${ }^{7 \mathrm{c}}$, Syed Ahmad Fauzan Syed Mohd ${ }^{8 \mathrm{c}}$, \\ Abdull Manaf Nordin ${ }^{9 d}$, Wan Fikree Wan Sa'uzi ${ }^{10 a}$, Muhammad Haris \\ Rahalim $^{11 a}$,Mohamad Syafiq Sahaimi ${ }^{12 a}$, Mohamad Akram Ahmad Badlishah ${ }^{13 a}$, \\ ${ }^{a}$ Centre of Diploma Studies,Universiti Tun Hussein Onn Malaysia (UTHM), Malaysia \\ ${ }^{b}$ Faculty of Civil and Environmental Engineering, Universiti Tun Hussein Onn Malaysia (UTHM), Malaysia \\ ${ }^{c}$ Kolej Kemahiran Tinggi MARA Sri Gading (KKTM Sri Gading), Malaysia \\ ${ }^{d}$ Kolej Vokasional Jasin, Malaysia
}

\begin{abstract}
Groundwater is one ofthe alternatives for water resource to meet the increasing demand ofclean water supply in Malaysia. Groundwater is water that accumulates in crevices of rock, soil and sand atthe bottom of the earth resulting from water flowing along the surface of streams or lakes. Many researcheshave been carried out to overcome theissues on demand and supply of clean water including the usageofgeophysics analysis with electrical resistivity method. The Vocational College in Jasin, Melaka was chosen as a potential area to detect the groundwater sources. Three horizontal lines were identified at the location namely Jasin-1, Jasin-2, and Jasin-3, before running the resistivity testing using the ABEM Terrameter SAS 4000. The protocol of Pole-Dipole was used for Jasin-1 and Jasin-2 while the Schlumberger was used for Jasin-3 in order to read the data. Then, the data was analysed using the RES2DINV software and presented in 2-dimensional images. Based on the findings, Jasin Vocational College is a potential area to produce groundwater with resistivity reading of 25 to $100 \mathrm{ohm}$ at 30 to 135 meter depth. Of the three lines, Jasin-1 was recommended as atube well potential spot. The analysis also shows that Jasin-1 area consistsof alluvium form sand, clay and gravel.
\end{abstract}

Keywords: Electrical Resistivity, Groundwater, Protocol

\section{Introduction}

Groundwater is the water present beneath the earth's surface in soil pore spaces and in the fractures of rock formation. The area of the water retained in the soil is called the saturated zone where the result of geological formations.The groundwater is collected and moved slowly through layers of soil, sand and stone known as Aquifer. Speed of the groundwater depends on the room size of soil or rock and how the room was connected. Groundwater can be brought to the surface naturally by the flow of water to the lake or through the drain. In addition, it can also be extracted by drilling wells into the aquifer[1].

Besides that, the groundwater supply can be improved by rain or melting snow. In some parts of the world, people are facing serious water shortages because groundwater is used faster than the rate of replenishment of groundwater supplies. Groundwater is a natural resource which is used in the life requirements, industry and agriculture. In some areas where the materials used on the surface is permeable and is contaminated, it could cause groundwater contamination. If the groundwater is contaminated, it is no longer safe to use. Therefore, it is imperative to preserve groundwater resources so that these resources can be used continuously.

\section{Materials And Methods}

Field work was carried out at the Vocational College in Jasin, Melaka. Figure 1 shows the location ofthe Jasin Vocational College. The college is located atBukit Telemong, Simpang Kelubi ona 40 acre land which was once an oil palm plantations area. Among the villages and placement available in the vicinity of the collage are Kampung Kelubi, Kampung Kesang Tua, Kampung Seri Kesang, Kampung Kemengkang, Felda Kemendor, Serkam Estate and Air Baruk. Investigation of groundwater in this study was carried out by using electrical resistivity method to determine the depth and specific location of the groundwater. 


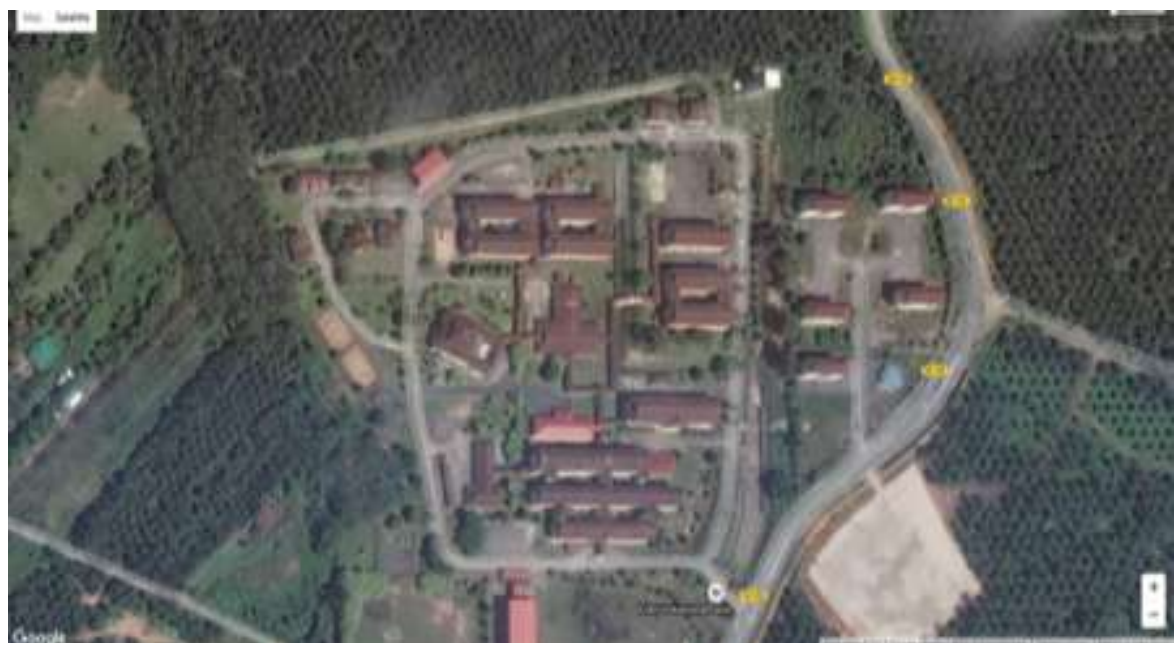

Figure 1: Google Earth view of Jasin Vocational College

Figure 2 shows the geological map of Peninsular Malaysia from the Malaysian Department of Mineral and Geoscience.
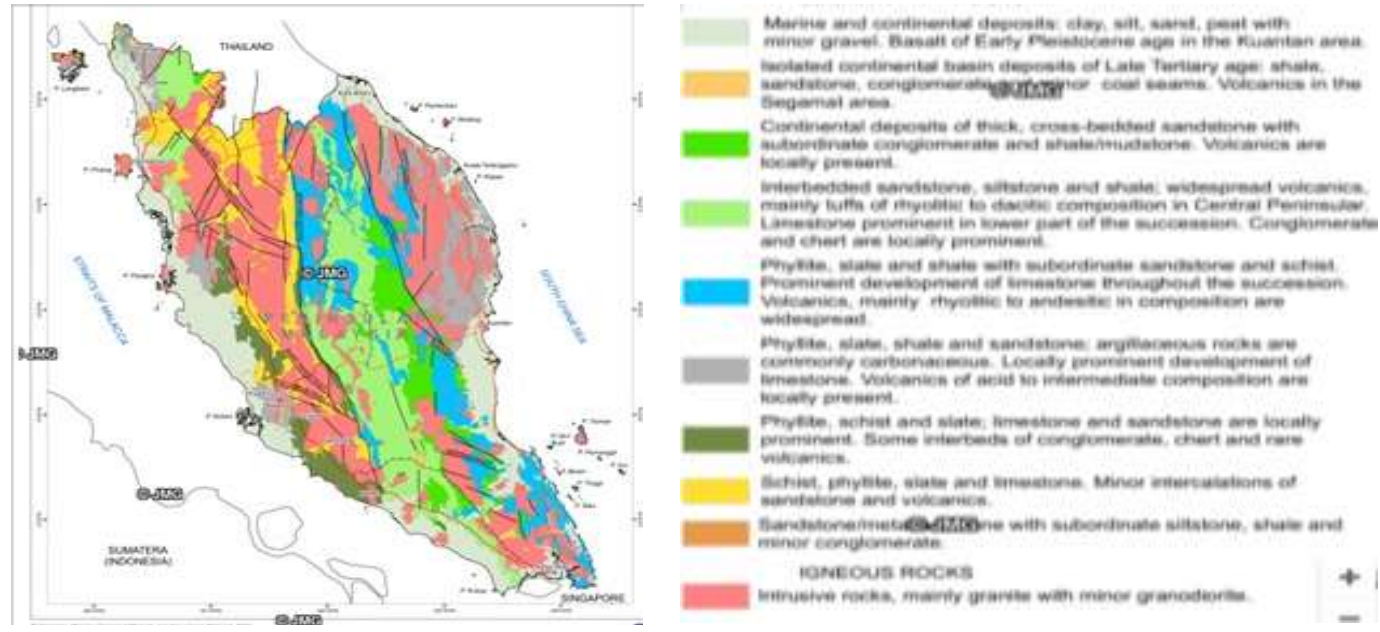

Figure 2: Geological maps

Source:Department of Mineral and Geoscience, Malaysia[2].

Referring to Figure 2, the potential to discover the groundwater in this area is quite promising based on the geological information of this area. There are several types of soil exist in Jasin which are phylite, schist and slate; limestone and sandstone are locally prominent. Some interbeds of conglomerate, chert and rare volcanics[3].Three cross-sectional lines were selected to facilitate the determination of the depth and location of groundwater by using the resistivity test. The selection ofthese lines was based on the distance of the span and land of terrain. The minimum and maximum spans to run the resistivity test are about 200 meters and 400 meters, respectively. All selected cross-sections have distances of 300 to 400 meters span.

The resistivity measurements are normally functioning by applyingelectric current into the ground through two electrodes namely $\mathrm{C} 1$ and $\mathrm{C} 2$, and measuring the resulting voltage difference at two potential electrodes namely P1 and P2. Apart fromthat, the electrodes selector is the device to select which electrode should be used to transmit the current for collecting data. The data were recorded to Terrameter and then were analysed using resistivity software. 
Site Investigation of Groundwater Potential at Jasin Using Electrical Resistivity Imaging

Table 1: List of the instrument that can be used to measure the resistivity

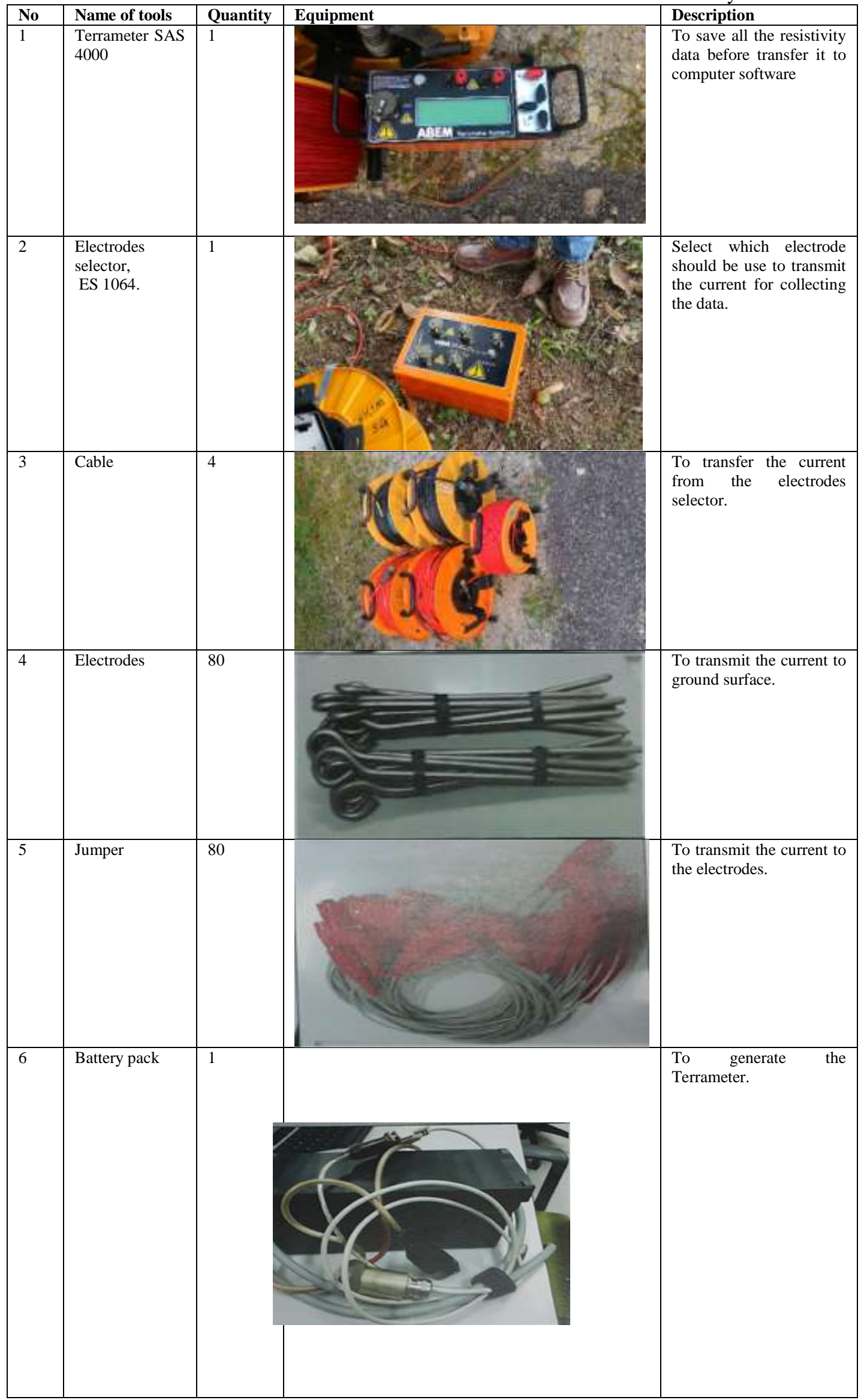




\subsection{Procedure of taking data}

Firstly, the horizontal lines must be selected; which are Jasin-1, Jasin-2, and Jasin-3. The selection of the lines must be selected based on the width or the area and the area also must be free from building structure obstacles during resistivity measurement works. Then to read the data of analysis, the Protocol Pole-dipole was used for Jasin-1 and Jasin-2 while the protocol Schlumberger wasused for Jasin-3. The Protocol Pole-Dipole and Schlumberger consist of two readings, as the Pole Dipole -Long (POLDIP4L) and Pole Dipole-Short (POLDI4S) while Schlumberger Short and Long (SCHLUM-L/S).

\subsection{The Field Arrangement for the ABEM Lund}

Figure 3 shows the outlines of ABEM Lund Imaging System in a 2D survey. Each mark on the cables indicatedan electrode position. The cables were placed along a single line (the sideways shift in the figure is only for clarity). Figure 3 also shows the principle of moving cables when using the roll-along technique. The total layout length depends on the spacing between the nodes, but is usually between 160 metres and 400 metres. The field arrangement steps are as follow:

1. The Lund imaging cable reel 1, 2, 3 and 4 were placed on the three horizontal lines. At JASIN_1, the cable of 5 metres spacing with 100 metres long at each of the ring was connected to cable 1 and 2. Meanwhile cable 3 and 4 wereconnected using the cable connector. The groove of the cable must follow the instrument direction at the edge of the cable.

2. Then the electrode must be planted into the ground at the depth of around $100 \mathrm{~mm}$ with 4.5 metres spacing for cable 2 and 3. For cable 1 and 4, an electrode wasalso planted with 9 metres spacing at the selected horizontal line which was next to the Lund cable. This wasto connect the electrode to the Lund cable by using the jumper.

3. Next the Lund Imaging cable wasconnected to the Electrode Selector where cable 1 and cable 2 were connected to Connector- 1 and cable 3 and 4 were connected to Connector- 2 .

4. Finally the multi cable from selector wasconnected to Terrameter SAS 4000.

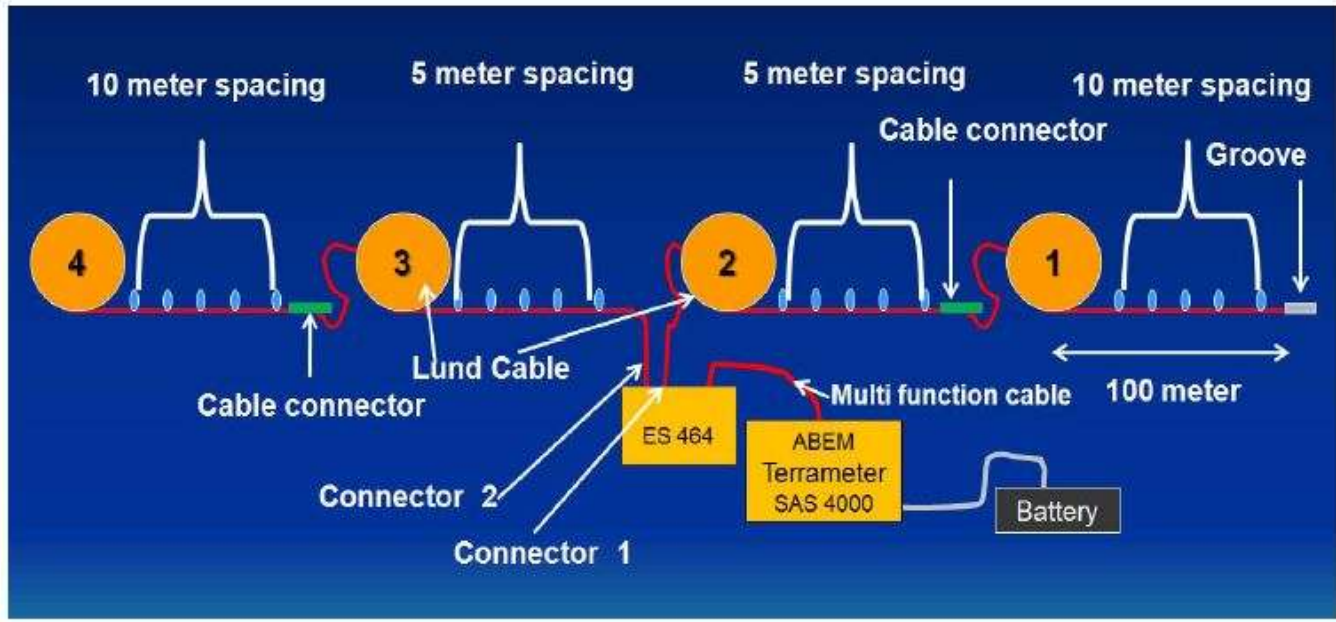

Figure 3: Field arrangement for ABEM Lund system

\section{Results And Discussions}

Table 2 shows the value of resistivity of rocks, mineral and chemical used in interpreting the 2D images obtained from the analysis. Generally, analysis outputs show the subsurface profile of Jasin-1, Jasin-2, and Jasin-3. As a whole, these resultsdetermine the type of ground and also detected the position and depth of potential groundwater source. 
Table 2:The value of resistivity of rocks, minerals and chemicals

\begin{tabular}{|c|c|c|}
\hline Material & Resistivity $(\Omega * m)$ & Conductivity (Siemen/m) \\
\hline $\begin{array}{l}\text { Ieneous and Metamorohic Rocks } \\
\text { Granite }\end{array}$ & $5 \times 10^{3}-10^{6}$ & $10^{-6} \cdot 2 \times 10^{-4}$ \\
\hline Basalt & $10^{3} \cdot 10^{6}$ & $10^{-6} \cdot 10^{-3}$ \\
\hline Slate & $6 \times 10^{2}=4 \times 10^{7}$ & $2.5 \times 10^{-4}-1.7 \times 10^{-3}$ \\
\hline Marble & $10^{2}-2.5 \times 10^{8}$ & $4 \times 10^{-10}-10^{2}$ \\
\hline Quartzite & $10^{2}-2 \times 10^{1}$ & $5 \times 10^{-6}-10^{-2}$ \\
\hline Sedimentarv Rocks & & \\
\hline Sandstone & $8 \cdot-4 \times 10^{3}$ & $2.5 \times 10^{-4}=0.125$ \\
\hline Shale & $20.2 \times 10^{3}$ & $5 \times 10^{-4} \cdot 0.05$ \\
\hline Limestone & $50-4 \times 10^{2}$ & $2.5 \times 10^{-3}-0.02$ \\
\hline Solls and waters & & \\
\hline Clay & $1-100$ & $0.01-1$ \\
\hline Alluvium & $10-800$ & $1.25 \times 10^{-3}=0.1$ \\
\hline Groundwater (fresh) & $10-100$ & $0.01-0.1$ \\
\hline Sea water & 0.2 & 5 \\
\hline Chemicals & & \\
\hline Iron & $9.074 \times 10^{-3}$ & $1.102 \times 10^{7}$ \\
\hline 0.01 M Potassium chloride & 0.708 & 1.413 \\
\hline 0.01 M Sodium chloride & 0.843 & 1.185 \\
\hline $0,01 \mathrm{M}$ acetic acid & 6.13 & 0.163 \\
\hline Xylene & $6.998 \times 10^{36}$ & $1.429 \times 10^{-11}$ \\
\hline
\end{tabular}

Source: Keller \& Frischknecht (1979); Daniels \& Alberty (1966 in Loke, 1999)[4]

Figure 4 shows the analysis graphical outcome of Jasin-1.

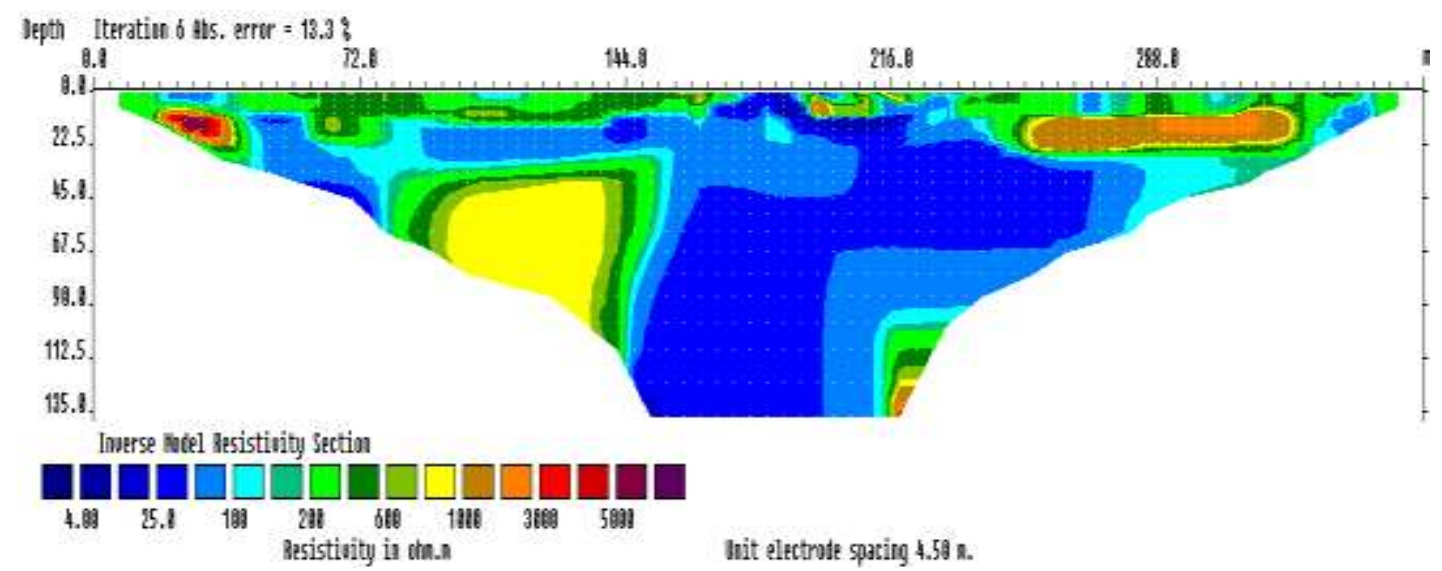

Figure 4: Result analysis data for Jasin-1

Referring to Figure 4, the line measurement for Jasin-1 resistivity was located at coordinate $\mathrm{N}$ $02^{\circ} 19^{\prime} 32.190^{\prime \prime}$ and E $102^{\circ} 24^{\prime} 30.575^{\prime \prime}$ with the length of 360 metres. The Pole-Dipole protocol was used for this field work locations with electrodes spacing of 4.5 meter for the short cable and 9.0 meter for the long cable. Using this protocol, the lowest resistivity data readings was between $4 \mathrm{ohm} . \mathrm{m}$ to $100 \mathrm{ohm} . \mathrm{m}$ at the depth of 30 metreto 135 metrewhich is the groundwater potential area. Previous study reported that water in sediment area has a resistivity value of 10-100 ohm.m[5]. Meanwhile, the medium resistivity data reading is between 100-300 ohm.m where waslocated at around 10-65 metre depth. Sandy clay has a resistivity value of 100-250 ohm.m[6]. Besides that, there is an area that has resistivity reading higher than $300 \mathrm{ohm} . \mathrm{m}$ and above showing the existence of sand and gravel with silt, slightly fractured bedrock with dry soil filled cracks and massive bedded and hard bedrock were 305 ohm.m, 305 - 2438 ohm.m and 2438 ohm.m and over respectively[7]. Figure 5 shows the analysis graphical outcome of Jasin-2. 


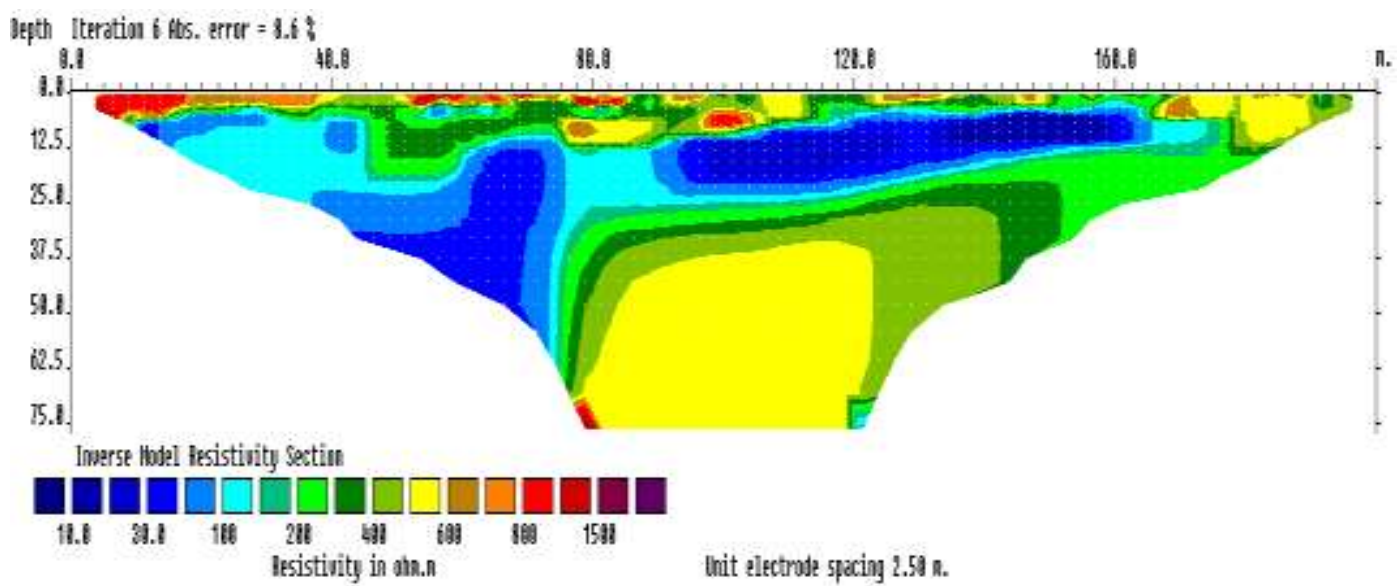

Figure 5: Result analysis data for Jasin-2

Referring to Figure 5, the line measurement is situated at coordinate N $02^{\circ} 19^{\prime} 19.629^{\prime}$ and E $102^{\circ} 24^{\prime} 34.228^{\prime \prime}$ with the length of 200 metre. For this line of measurement, there were two types of protocol been used which were Pole-Dipole and Schlumberger Protocol. The electrodes spacing for this line of measure is 2.5 metrefor short cable and 5 metrefor long cable. By using the same electrodes spacing for both protocols which, two different readings of resistivity data can be analysed from this line of measurement. For the PoleDipole Protocol, data of resistivity reading can be divided into three level which are the lowest, medium and highest. The lowest resistivity data reading between 10-100 ohm.m at the depth of 10- 65 metre. While, the medium resistivity data reading is between 100-300 ohm.m at 5-10 metreand 20- 70 metre depths. There weresome areas that showed the reading of resistivity data higher than $300 \mathrm{ohm} . \mathrm{m}$ and above. Meanwhile, for Schlumberger Protocol, at the depth of 5-40 metreshowedthat the reading of resistivity data was between 15-100 ohm.m. While, at the depth of 5-10 metrethe resistivity data reading wasaround between 200-500 ohm.m. Based on the analysed data, it shows that this area has no potential of groundwater sources. Figure 6 shows the analysis graphical outcome of Jasin-3.

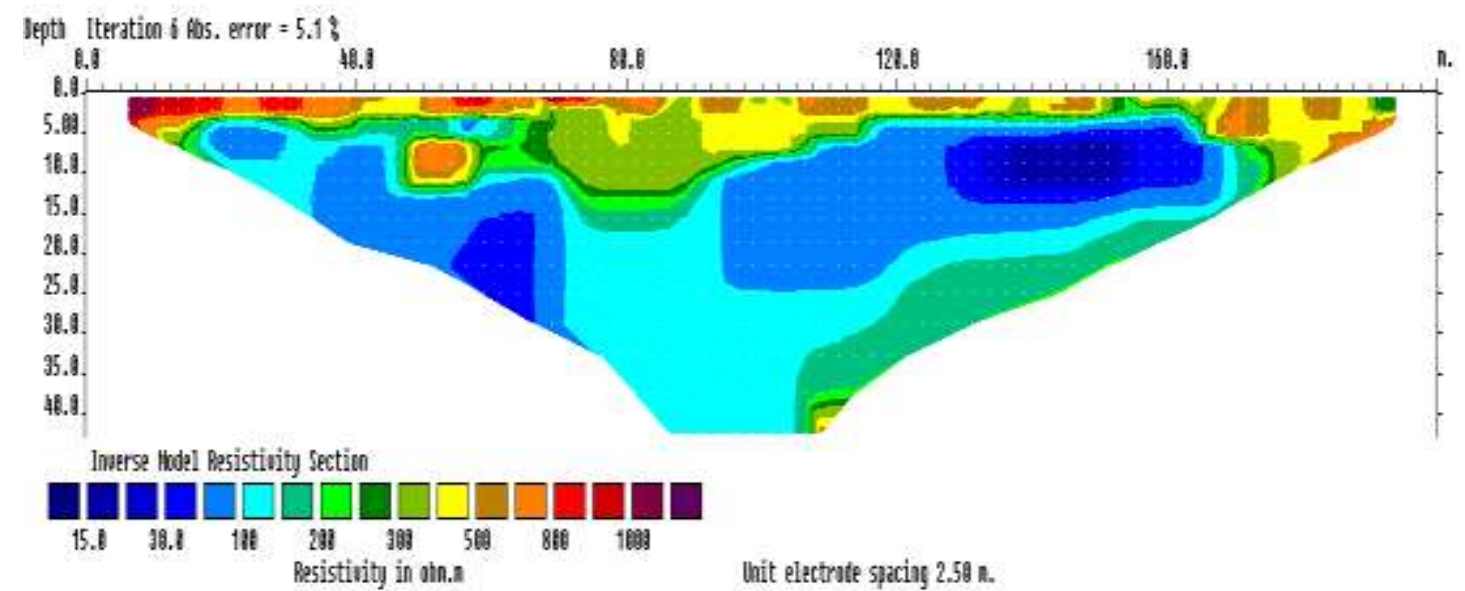

Figure 6: Result analysis data for Jasin-3

Referring to Figure 6, for Jasin-3, Pole-dipole and Schlumberger Protocol also has been used.This line of measurement waslocated around 300 metresfrom Jasin-1 area. The electrodes spacing for this line of measure was 2.8 metrefor short cable and 5.6 metrefor long cable. The resistivity reading showed that at the depth of 1040 metrethe reading of resistivity data was between 4-100 ohm.m which at this depth it can be considered as subsurface water and less potential as groundwater source. From the depth of 50-80 metre, the resistivity data reading was 200-600 ohm.m. Based on that it showedthe subsurface profile of this area was slightly fractured bedrock with dry soil filled cracks massive bedded and hard bedrock. While by using the Schlumberger Protocol it has shown that this area was less potential to consist of groundwater source at the depth of 5-40 metrewith resistivity reading between 7-100 ohm.m. 


\section{Conclusion}

It can be concluded that the geophysics analysis using the resistivity method has successfully reached its objective to identify the position of the groundwater. Hence, the finding can be an evidence that mineral water can be obtained from the study area. Of the three lines, findingsshowed thatJasin- 1 has the highest of mineral water than other areas. In addition, the method usedwould betime and energy saving. This method can also be applied to otherfields such as civil engineering, building site design, archeology research, geoengineering and many more. Since water pollution in this country has increasedday by day and so as the clean water sources is declining. The option is by using groundwater that has been proven cleaner than the surface water. Lastly, the nature has to be preserved and taken care ofin order to maintain the ecology system.

\section{Acknowledgements}

The authors gratefully acknowledgethe Centre of Diploma Studies,Universiti Tun Hussein Onn Malaysia (UTHM) for the financial support. Special thanks to the Jasin Vocational College, Melakafor the cooperationin this research.Thanks also to the Kolej Kemahiran Tinggi MARA Sri Gading(KKTM Sri Gading) especially for the equipments support and not to be forgotten, En. Mohd Roslan bin Mohamed Safani from the Hijrah Mahabbah Resources Company for histechnical advicesand networks.

\section{References}

[1] W.M.Telford, L. P. Geldart, and R. E. Sheriff, "Applied Geophysics,” 1976.

[2] "Mineral and geoscience department of Malaysia," 2015. [Online]. Available: www.jmg.gov.my.

[3] D.F. McCarthy, Essentials of Soil Mechanics and Foundations Basic Geotechnics, Pearson In. New Jersey, 2007.

[4] G. V. Keller and F. C. and Frischnechk, "Electrical Methods in Geophysical Prospecting.," PergamonPress, 1979.

[5] M. Kaamin, M. F. Tajul Baharuddin, and W. W.C., "Pencarian kawasan air bumi di daerah Batu Pahat menggunakan Sistem Maklumat Geografi (GIS)," Universiti Tun Hussein Onn Malaysia, 2006.

[6] T. S. Lee, Slope Stability and Stabilization Methods. New York: John Wiley \& Sons, Inc, 2002.

[7] M. A. Derani, "Study Of Seawater Intrusion By Using Time-Lapse Resisitivity Measurement at Alluvial Coastal Carey Island,Selangor," Universiti Tun Hussein Onn Malaysia, 2010. 